\title{
Disrupting the Metanarrative: A Little History of Image Indexing and Retrieval
}

\author{
Pauline Rafferty \\ Aberystwyth University, Department of Information Management, \\ Libraries and Archives, Aberystwyth SY23 3UX, <pmr@aber.ac.uk>
}

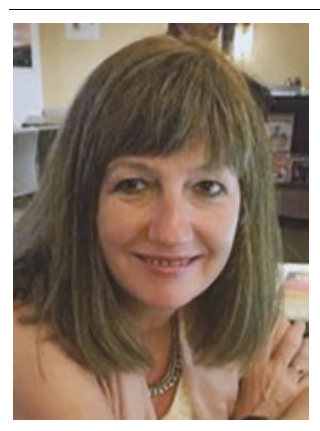

Pauline Rafferty is Senior Lecturer at Aberystwyth University, teaching knowledge organization and representation, information architectures, and qualitative approaches to research. Her research interests include knowledge organisation and cultural documentation, and critical communication and information studies. Specific areas of interest include popular culture in and through the web, the democratisation of critical authority, and participative digital cultural production. She holds a PhD in critical theory and cultural studies. Pauline is Joint Editor of Journal of Information Science and Joint Regional Editor of The Electronic Library. She has co-edited books for Facet and co-written a book for Ashgate.

Rafferty, Pauline. 2019. "Disrupting the Metanarrative: A Little History of Image Indexing and Retrieval." Knowledge Organization 46(1): 4-14. 83 references. DOI:10.5771/0943-7444-2019-1-4.

Abstract: The aims of this paper are twofold: to offer a short history of image retrieval, and secondly and relatedly, to critique the metanarrative of modernity emerging in the literature of knowledge organization and information retrieval. The paper reviews the emerging grand narrative in relation to knowledge organization and information retrieval that sees them as specific aspects of modernity and technological efficiency. This grand narrative is particularly interested in technology even when it is contextualising technology. A more nuanced history emerges when the focus moves to the representation, organization, and retrieval of images. This literature foregrounds not only the technology but also issues relating to definitions of the "subject" and issues relating to interpretation and meaningmaking.

Received: 18 September 2018; Revised: 26 November 2018; Accepted: 10 December 2018

Keywords: information systems, image retrieval, image indexing, images

\subsection{The technological grand narrative}

In the introduction to their special issue on the history of information systems, Bryant et al. $(2013,1)$ remind us that histories are made as much as they are discovered and refer back to Carr (1961) and Collingwood's (1994) view that that the relationship between the past itself and the historian's thought is key. There is no one definitive and authoritative information systems history, "on the contrary, the process of articulating the history of IS needs to be a wide-ranging, continuous effort, encompassing different perspectives and agendas." That the history of information science should be of interest is not surprising given the importance of digital information systems in our modern world. For some scholars working in critical information science contexts (e.g., Day 2008), it is the discursive formations of the present that become the drivers toward a critical interrogation of generally accepted stories of the past. Recently there has been considerable scholarly interest in historicising and critiquing information with reference to the metanarrative of modernity (see for example Day 2008 and Hayles 2008). In this retelling, information science and information systems are contextualised within the broader metanarrative of modernity, so that modern information management is characterised as emerging from a worldview that privileges facts and science, assumes stability in textual meaning, and believes in the disinterested and objective authority of the professional indexer. Such histories point to the pursuit of facts in documents that underpins Paul Otlet's work (Rayward 2014), the notion of the informational unit, comprising facts and opinions that unpins the systematic indexing of Julius Kaiser (Dousa 2007), Suzanne Briet and the post Second World War documentalists, and the development of computerised information retrieval and the distributed power of the World Wide Web.

Rayward (2014, 683-84), acknowledging the need for simplification to impose [narrative] order, identifies three "information revolutions:" the Gutenberg revolution, the pre-digital post-Second World War age, and the digital age. Whilst emphasising the driver technologies for each of these revolutions, Rayward contextualises them with reference to the broader socio-economic parameters within which they have been designed, developed and used. Print technologies developed within the emerging capitalism of Europe and the systems that were designed to the manage 
information were responding to the needs of competitive companies, organisations and governments who looked to expand while at the same time they sought to communicate with others on an international level. Information, textual, graphical and statistical, delivered by print, by telegraph or other means, underpinned capitalist growth. Alongside the technological developments and the expansion of informational genres came information management developments such as the growth of bibliographies, national and professional, classification tools and the development of faceted approaches to classification.

The information revolution of the post Second World War period focused on scientific and technological information that grew out of the activities of the war years but shifted to commercial industrial and medical information as well as military information. The indexing of this documentation was crucial and conventional solutions were considered to be too slow and not fine-grained enough for the work (692). Speed of access, precision in retrieval and technical expertise in indexing were seen to be crucial elements in information management. The arrival of computerised systems from the 1950s drove the design of computerised indexing systems such as KWIC and KWOC indexes before the emergence of database systems and the subsequent development of cataloguing, indexing and thesaural standards and cooperative cataloguing initiatives.

The third, digital revolution, is a revolution of ubiquity, as access to digital information is possible through a plethora of devices accessible on the go to anyone who can afford to access them and knows how to use them. Document creation and reproduction techniques have been freed from the restraints of older technologies, and document creation in the public sphere of the web is now open to the general public without the quality constraints of conventional publishing (704). New communicative genres such as blogs, emails and tweets have developed, while social networking sites such as Facebook, Instagram, YouTube and Flickr allow for the creation and dissemination of non-textual documents such as images and music. There is some debate about whether the changes that have come with the digital age point to some fundamental shifts towards a post-modern, surveillance driven digital economic age or whether these shifts, while clearly significant in their velocity, their convergence and their technologies, are essentially a continuation of the information age in that all societies and human ages have been, and are information societies (704-705).

That, broadly and generally speaking, is the story. There are variations on the story, such as Day's Indexing it All (2014), that take a slightly darker view about issues regarding ubiquity and the human "subject" in relation to information technology. In this darker version, while infor- mation technology facilitates access to knowledge, at the same time humans are becoming known "subjects" in and through retrieval systems (see, for example, debates about Facebook and its methods of collecting information about its users in Bennett and Livingstone (2018) and Schou and Farkas (2016)). Hayles (2008) distinguishes between the humanity of the modern Enlightenment, and the posthuman, which derives from a view that privileges an abstract idea of information and sees human identity as being essentially an informational pattern. Hayles traces an historical trajectory of this cyborgian worldview from Shannon and Weaver through cybernetic theory, and in the process points to the skim reading mode of perception that comes with the screen reading information overload of the digital age, arguing for the literary method of "close reading" as a strategy to offset the surface of the machine.

Within this broad historical framework sit a variety of knowledge organization tools designed and developed within specific epistemological frameworks dominant at the cultural-historical moment of their creation and initial development. Discussions about the great universal classification schemes of the late nineteenth and early twentieth centuries often include reference to modernist assumptions regarding fact, objectivity, and science that underpin their creation (Mai 1999 and 2004; Rafferty 2001). Specialist indexing tools such as professional, domain specific thesauri developed to support the increasing specialisation and commercialisation of information post-1945 (for an historical overview, see Rowley 1994 and Sanderson and Croft 2012). In addition, the development of thesauri offered a solution at a time when interdisciplinary research threatened to make the rigid discipline-oriented structures of the classification scheme seem obsolete or at least cumbersome, and they offered a way of reconciling subject headings and classification schemes that makes it easier to switch between both (Garcia-Marco 2016, 6).

Within this metanarrative, social tagging and user generated content are sometimes seen as postmodern and disruptive approaches to knowledge representation. In this story, social tagging has the potential to unlock the emancipatory possibilities of digital technologies and systems and counteract the potential gloom of technological tyranny and the indexing of the subject. Champions (e.g., Kroski 2005; Shirky 2005; Merholz 2004) laud the flexible, participative and collaborative nature of social tagging, which is democratic (Rafferty and Hidderley 2007) in that it involves all users, and emergent in that the tags can change rapidly in response to new content (Feinberg 2006). Early proponents of social tagging took inspiration from Surowiecki's (2005) notion of the "hive mind" or the "wisdom of crowds" or "social intelligence" to explain the advantages and richness that they claimed for social tagging. The idea is that the combined intelligence of a group 
of people will be greater than the knowledge of an individual, even an expert individual. Although even early on in its history there were critics of tagging (see for example, Kroski 2005; Guy and Tonkin 2006; Rafferty and Hidderley 2007), in this story, tagging is seen as inclusive, incorporating no imposed cultural or political bias; its language is current, fluid and capable of incorporating terminology and neologisms (Garcia-Marco 2016); it is non-binary, democratic and self-moderating, follows desire lines (Mathes 2004) and engenders community.

\subsection{An image retrieval story}

Image retrieval has its own technologically-oriented story, which moves from domain specific thesauri through to content-based information retrieval (see Benson 2015 for an historical overview of some of the issues relating to image indexing). In this story, information retrieval solutions in the pre-digital library environment generally derived from the development of specialist knowledge organization tools such as the Library of Congress Thesaurus for Graphic Materials (LCTGM)( https://www.loc. gov/rr/print/tgm1/), the Getty Institute's Art and Architecture Thesaurus $(A A T)$ and the Netherlands Institute for Art History's Iconclass (http://www.iconclass.nl/home), tools that grew out of the pre-digital, post-Second World War golden age of specialist controlled vocabularies and thesauri. The LCTGM, which started in 1980, was a consolidation project drawing together subject terms that had been used for fifty years in the division's manual files and the local subject headings lists. Its development coincided with the publication of the ANSI Guidelines for Thesaurus Structure, Construction and Use and the thesaurus software package, Lexico (Alexander and Meehleib 2001). Work on the Art and Architecture Thesaurus began in the late 1970s as art libraries and art journal indexing services were computerizing their catalogues. The $A$ AT's own history page (http://www.getty.edu/research/tools/vocabular-

ies/aat/about.html\#history) notes that while thesauri and controlled vocabularies were developed in sciences before this point, "the use of a thesaurus for indexing was not welcomed by art catalogers prior to the advent of computerized cataloguing." The principles of the $A A T$ thesaurus were established by 1981. Iconclass is an iconographic classification system devised by Henri van de Waal of Leiden University. It took forty years for this system to be developed resulting in seventeen printed volumes published between 1973 and 1985.

So far, this story resembles the more general narrative in that specialist controlled vocabularies are created to impose order on to the image information chaos, and the standardisation of information management allows for cooperation and control. As computerisation developed dur- ing the course of the late twentieth century and early twenty-first century, content-based retrieval solutions were developed for managing images. Content-based systems often focus on the retrieval of specific images, a large set of images stored in a digitised database by interrogation using some form of indexical surrogate, often a specific attribute, for example shape, colour, texture. Historically, issues relating to ambiguity and human interpretation were challenges that early research programs had to overcome, to bury, or better still, avoid altogether by focusing research on images whose function is monologic in nature, in enquiry situations that are relatively unambiguous systems for retrieving logos, maps, images of textiles (Hidderley and Rafferty 2007).

Social media and mobile computing technology have developed at such a rate that there has been a tremendous growth in the availability of online images, and this development has been accompanied by an increasing interest in designing smart content-based systems that can incorporate semantic search (see for example Zhu et al. 2017, and Ristoski and Paulheim 2016 for overviews), and while the discourse of user-based indexing often foregrounds democracy and user emancipation, approaches to post-hoc disciplining of tagging practice remain popular (see for example tag recommender systems, and the display of "interesting" or trending tags reported by Dubinko et al. 2007). Related approaches include incorporating user behaviour into image retrieval systems, for example, browsing behaviour (Trevisiol et al. 2012), sentiment analysis (Chen et al. 2014) and click-through behaviour (Pan et al. 2014). Computational approaches to the challenges of very large web-based image repositories have also included the development of computational aesthetics solutions, though the developers of such systems differentiate between the "true aesthetics value," determined by genre, context and semantics of the artwork, and also possibly by the sophistication of the viewer, and which can perhaps only be fully identifiable when the sample size is infinitely large and when there is no noise in the observation, and the "observed aesthetic" of artworks, which can be obtained from a pool of values drawn from experts and general viewers (see, for example Datta et al. 2006 and Joshi et al. 2011). Such systems rely on a baseline set of interpretations drawn from human feedback, perhaps through tagging, that could then be used to develop automated recommender systems.

Overviews of the history of content-based image retrieval (CBIR) generally survey such systems before engaging with the issue of the "semantic gap" and the development of semantic CBIR systems (see Alzu'bi Amira and Ramzan 2015 for an overview). The semantic gap in image retrieval refers to the difference between the low-level information retrieved by a computer and the high-level se- 
mantic image information understood by the user. The semantic gap is interesting, because emerging early on in the history of computerised information retrieval, it points to a disruption in the story of smooth efficiency (even when the efficiency might contain dark and sinister undertones) that drives the metanarrative of computerised information management. Interpretation matters in relation to images and the challenge of meaning-making in image retrieval foregrounds more general knowledge representation concerns relating to hermeneutic interpretation, connotation and associative meanings, and allows for an interrogation of the monologic authority of the curatorial keyword.

\subsection{Images, "subjects" and phenomenological de- scription}

That the "semantic gap" was recognised and drives the history of the information management of images within both computer science and information science (see for example, Gudivada and Raghavan 1995 and Hare et al. 2006) shows the metanarrative of the efficient computerised retrieval system being unpacked earlier in this subfield than the more general critique of monologic knowledge organization tools that sometimes informs discussions of web-based digital information management (see for example, Shirky 2005). The recognition of the semantic gap points to the telling of another story focused on subject representation, phenomenal description and interpretation. In this story, it is perhaps useful to distinguish between the knowledge-based linguistic written signs that have traditionally been the focus of conventional knowledge organisation research and development, and other kinds of signs that are not necessarily knowledgebased signs, in relation to which semantic and affective meanings might be more open to reader, listener or viewer interpretation. The image retrieval disruption comes with the acknowledgement that the interpretation of visual signs and images is not quite the same as the interpretation of textual signs and language, particularly when the visual signs are not accompanied by text to anchor the meaning of the image.

The issue of subject indexing in relation to images starts to become a significant one in the literature from the 1980s onwards, with writers such as Michael Krause (1988) and Sara Shatford Layne (1994) exploring meaning and interpretation in relation to images, Krause distinguishing between "hard meaning" or what is observed in a picture, and "soft meaning," or the subjective meaning, while Shatford Layne distinguished between "ofness" and "aboutness." Shatford Layne, who has played a major role in exploring issues around the interpretation and signification of images in the specific context of image indexing, draws on the literature of philosophy of art, meaning in language and visual perception to analyse the levels of signification inherent in and through pictorial images.

Shatford (1986), drawing on Erwin Panosky's three levels of meaning in art images, constructed a conceptual framework through which to identify the semantic elements within images that might be useful in constructing image indexing solutions. The original conceptual framework constructed by Panofsky to help with the interpretation of Renaissance art consists of three levels of "meaning," which are:

- Primary level of meaning or sphere of phenomenal meaning: subdivided into factual (a depiction of a human being) and expressional subject matter (Panofsky 1993, 54). This is the pre-iconographical level of art.

- Secondary level of meaning, dependent on knowledge of codes, culture and conventions: identifying the male figure in the painting with the knife as St. Bartholomew. This level of subject matter is called the iconographical level of art.

- Intrinsic meaning or content: depends on the viewer synthesising information gathered at the first two levels of meaning with additional information, which might include information about the artist and the socio-political cultural moment of production. Achieving iconological interpretation depends on "synthetic intuition," an attribute which might be more often found in the talented layman than the erudite scholar (Rafferty 2011, 283).

The iconological has sometimes been interpreted as the subjective element in the interpretation of images (see for example, Enser 2000). Panofsky, however, relates the iconological to the broader socio-economic context, the logonomic parameters in social semiotic terms (Hodge and Kress 1988), or psychological interpretations about the artist, which suggests that Panofsky envisages certain kinds of viewers or "readers," whether scholars or talented laymen, undertaking the interpretation of the Renaissance art image. Some of this assumption about the indexer as expert or talented reader underpins the literature of image subject indexing that followed Shatford-Layne, Enser and Jörgensen's leads (see, for example, Bohnsack 2008).

Shatford interprets Panofsky's pre-iconographic level as "generic of;" the iconographic level is treated as "specific of;" and the iconological level is treated as "about" and includes four facets of indexing description (who, what, where and when) to produce a matrix of indexing possibilities (Shatford 1986, 43). Armitage and Enser (1997, 287) adapted the framework to include four main categories (who, what, where and when), and three levels of abstraction: generic (pre-iconographic), specific (iconographic) and abstract (iconological). Collins (1998) argued 
for more pre-iconological or generic level description of the content of images, an approach that Jörgensen (1998) also highlights, focusing on the ways in which users search for images. In the project reported in the 1995 and 1998 papers, Jörgensen sought to discover the range and types of features needed to describe the contents of an image. She sorted terms that were spontaneously added to images through describing, searching and sorting tasks undertaken by research subjects under quasi-experimental conditions. The results led to the development of her baseline framework of twelve attributes and three categories (perceptual, interpretative and reactive), which have been used in other studies (for example Jansen 2008, and Rorissa 2010). The perceptual attributes come from looking at the image, the interpretative attributes require some personal interpretation and may be in the eyes of the specific viewer, while the reactive may include conjecture and emotional responses.

When the Shatford matrix was used by Choi and Rasmussen (2003) to study queries from students of American history, they discovered greater use of generic terms, with generic people or things, events and locations occurring most frequently. It would seem that different user groups within different domains have different image information needs. Conduit and Rafferty (2007) attempted to draw together the different facet frameworks in a study that also mapped archivists' views into a meta-framework but it is very difficult to construct frameworks for mapping interpretation of images, even if the interpreter is a domain expert trained in indexing, not least because, as Armitage and Enser (1997) point out, it is difficult to know the right category in which to place things.

These approaches to image indexing highlight the complexity of dealing with the subject in non-textual information objects whether we are concerned with analogue or digital systems. The technologies may allow us to construct more efficient ways of producing and reproducing images, of storing, transmitting and accessing images. Yet, the subject problem is still there to be addressed, and the phenomenal descriptions that these systems envisage, while interrogating the metanarrative of the efficiency of computerized systems, still depend on the description being undertaken by the expert indexer/reader on behalf of the information seekers.

\subsection{User generated content, tagging, landscapes and flaneurs}

Alongside the development of frameworks for phenomenal descriptions of images and the associative meanings of images, a considerable amount of research from the 1990s onwards focused on how and why people searched for images, exploring whether this knowledge could help us to construct superior computerised image retrieval systems. In many regards this move mirrors the more general move towards user behaviour research from the 1980s onwards. The research generally suggested that the further away the information retrieval scenario was from the professionally mediated archival context, the greater the significance of browsing features (Enser 2008, 534). Feedback and user interaction features also enhance the browsing approach to image retrieval.

Fidel (1997) captures this insight in the development of the image seeking continuum, which has the "object pole" and the "data pole" as the extreme points of the continuum. Fidel explains that images can be used in different ways, so that an icon representing wheelchair accessibility is very different from the use of a colourful picture on a wall (187). The icon is the image as the source of information (there are many assumptions in this observation of interest to semioticians) and the picture is the image as object. The "object pole" refers to image searches in which the interest is in retrieving a specific image, so that specificity and relevance are of considerable importance. The "data pole" refers to the need to retrieve information or objects that the image portrays. Relevance feedback becomes increasingly important towards this pole.

Smeulders et al. (2000) divided image searching for images into three categories: search by "association," "target" search and "category" search. Search by association aims to find interesting things. The results can be manipulated interactively by providing user feedback. Systems that support this category are highly interactive and support browsing. Target search aims the search at a specific image. Category search aims to find an arbitrary image representative of a specific class (1351). They explain that this is not the whole story however, and distinguish between narrow and broad domains, arguing that in the broad domain, images are polysemic and their semantics can be described only partially (1352).

And this takes us to another story, about stories and storytellers, about interpretative hermeneutics and the writerly nature of images. In the early 1990s, when computerised information retrieval was still relatively specialist, some writers speculated about whether digital information retrieval systems could facilitate a multi-voiced approach to indexing images (for example, Hidderley and Rafferty 1997). They took the view that conventional approaches to image indexing both facilitate and discipline access and discovery, and suggested that information system designers should encourage more democratic approaches to image indexing. One might critique the use of the term "democratic" in this early work, and point to the automated and instrumental means by which a consensus view was to be sought in the theoretical framework (see Mai 2011 for a constructive critique), but it is worth recalling 
that these theoretical musings were undertaken at a time before the web became ubiquitous, when relatively rigid frameworks for designing computerised information retrieval dominated. The early work was necessarily limited, but it opened up some space for further discourse.

The work done on analysing user requests for images by Enser, Jorgensen and Fidel, amongst others, revealed the importance of browsing and the more general search by association and also category types of searches that people undertake in large, unmediated image collections. This revelation pointed towards the development of browsing and enhanced discovery and access mechanisms in and through web systems; we can see this also in relation to web-based text searching, for example in the development of tagging, but it was image information seeking research that revealed the importance of browsing, feedback and interpretative and reactive categories within unmediated and ubiquitous digital information environments (i.e., the World Wide Web) as far back as the early 1990s.

Something of the desire for a more democratic approach to retrieval that acknowledges and values feedback, user engagement and browsing can be seen nowadays in social tagging-based systems, and image tagging, which along with music tagging, emerged as an important research front in the early 2000s (see for example, Trant 2006). Matusiak (2006) compared and contrasted professionals' metadata with image creators tags on Flickr, finding that although the tags were unstructured and "sloppy," they are also richer, more current and multilingual. More recently, Baldoni et al. (2012) combined affective computing, social tagging and ontologies in relation to artworks with the end goal of representing the emotional tags derived from user interactions as emoticons. While the tagging and folksonomy approach might allow for a wide range of voices to be heard, the burden of judging relevance is then on the information seeker. Recent approaches to information system design have focused on the figure of the information seeker and the goal of designing systems that can deal with the information overload generated by digital information.

Drawing on the literature of information seeking, with its focus on the user experience, the human-centred understanding of the research process, its interest in the everyday, the serendipitous and the exploratory, and including the notion of the flaneur, found in literature dating back to 1840 s Paris and associated along the way with literary figures such as Baudelaire, Simmel, Walter and Benjamin, Dörk, Carpendale and Wiliamson (2011) sought to create new interface models that offer various and varied pathways through information spaces. They distinguish between the conventional utilitarian and task-based approaches to conceptualising information seeking and the casual, playful and pleasurable perspectives that might well be more appropriate in relation to some, if not all, information seeking activities around digital cultural information, including images. In their research, the "information flaneur" is a metaphor that inspires a new way of thinking about information seeking. For Dörk, Carpendale and Williamson, the "information flaneur" is "an urban wanderer, who leisurely walks through the streets and squares interpreting and re-imaging the city" (1). The "information flaneur" sees beauty and meaning in growing information spaces. Their flaneur is:

- Curious Explorer: passing through squares and crowds, making sense of the city without becoming fully part of it. He keeps his own leisurely pace in resistance to the growing pace of capitalism.

- Critical Spectator: fascinated by the commercial spectacle but also aware of the social realities accompanying modern life.

- Creative Mind: viewing the urban story as epic heterogeneity, the flaneur is an interpreter making "the urban landscape legible and meaningful. He has the ability to relate to the world through multiple facades" (3)

Envisioned as the information flaneur, this information seeker's seeking activities are embedded into everyday practice, he uses many information tools: sometimes he moves towards information targets, sometimes uses visualisations. As a critical user, he avoids excessive filtering, enjoys bumping into information and cultivates an open mind to find hidden connections. He enjoys exploring unfamiliar information spaces, new information discoveries and makes personal meaning. The "information flaneur" follows clues and links and hunches to read the stories in the information space.

Based on this persona, Dörk, Carpendale and Williamson suggest a model of information design that privileges:

- Orientation: including situated navigation, contextualisation, faceted navigation and visualisation;

- Visual Momentum and information visualisation: for example, animated transitions, zoomable interfaces and detail-on-demand; and,

- Serendipity: juxtapositioning researchers who share unusual facets or relate to previous interactions.

This move towards the human-centred information seeking and the serendipitous pleasure oriented exploratory aspects of information seeking has influenced the development of the "generous interface" (Whitelaw 2012 and 
2015), which offers rich, browsable views, provides samples of the content and supports contextualised displays. Whitelaw $(2015,7)$ suggests some general principles for the creation of more generous cultural information interfaces:

- Show first, don't ask: volunteer information that supports the audiences' understanding;

- Provide rich overviews: and help to orient the users' explorations;

- Provide samples: to provide rich contextualised clues and invite explorations.

Another recent information metaphor that draws on some of the "information flaneur" approach is the notion of the "pathway" through cultural content as used, for example, by Wray, Eklund and Kautz (2013) to design retrieval systems for digital art collections. The focus here is on connectedness while designing approaches that follow visitors' interests and perspectives rather than imposing only one authoritative, curatorially informed view. They point to two emerging trends in interactions of digital objects in information spaces:

1. Expansion of information spaces: Massive scale and federated availability that allows sharing of knowledge, avenues for exploration and meaning making (Cairns 2013) and encourages personal exploration and appropriation of collections from institutions to communities of interest.

2. Recognition of pleasure, aesthetics and play: relating the experience of engaging with digital artworks back to idea of Homo Ludens (Huizinga 1971).

Related to the "information flaneur" and the "information pathway" (and in tagging literature, desire lines) is the metaphor of the "information landscape," which calls for exploratory searching, feedback and innovative approaches to mapping, shifting and managing "information horizons." The phrase information horizons is suggestive of Jauss' (1970) horizons of expectation and the possibilities this framework offers for an historicised understanding of the reader-author dialectic in meaning making and the diachronically shifting nature of genre. Something of that same acknowledgement of the diachronic transformations in information search and discovery resides in the notion of the "information flaneur."

In the literature of the 1840s and in Benjamin's work, the flaneur walks through the city of sometimes dreadful delights, with a critical eye, sometimes a sardonic eye on the consumer society of modernity. We could, following Dörk, Carpendale and Williamson re-envision, the "infor- mation flaneur" as the information seeker; the web, with its teeming, sprawling, labyrinthine information sites, is the equivalent of the dreadful delights of the city, but in the literary metaphor, the flaneur moves within a city of people, not just a city of buildings, architectures, arcades and glittering objects, and in the peopled city, the flaneur moves through fragments of story: newspapers stories, gossip, chattering crowds, language, image and information. Moreover, the peopled city has its history, fragments of which not only survive but form and inform the contemporary moment. The flaneur reads the peopled city for information in and through crowds.

The "information flaneur" inspired designs that we have to date are still curatorially centred, but there may be space to create approaches to discovery that draw on the rich and serendipitous encounters in the virtual cityscape of the web. Such spaces might allow us to build into search and discovery approaches the stories and fragments and gossip and reminiscences of the crowd, so that, in relation to at least some types of image search, we might move towards multi-voiced descriptions of images, as tagging allows, but go beyond the paradigmatic plane of single word or mashed up tags, to the syntagmatic descriptions that storytelling allows.

The notion of the "writerly" text and the "readerly" text (Barthes 1974) is perhaps of some interest here. The writerly text points to texts in which the reader is given space to interpret the text, while the readerly text is a text in which meaning is more clearly determined by the author, and beyond the specific author, by the codes and conventions relating to the genre or form within which the author is working. Images, particularly those that do not have text to anchor meaning, allow us to focus on the writerly text. The writerly text lets us connect human to human, in the historical present, across historical time and their interpretative potential is open to shifts and changes and multi-various interpretations. In the era of tagging, Rafferty and Albinfalah (2014) undertook an exploratory study that investigated storytelling as an approach to developing a template for the input side of image description through digital collections. Their study was necessarily small and narrow and took a quasi-experimental approach that asked research subjects to provide narrative descriptions of two images, which while they were highly modal, were arguably writerly images that invited interpretation. The storytelling approach produced a broad range of connotational responses that could be used to construct rich discovery tools.

The interest in developing rich user-generated descriptions in image retrieval stretches back several years. In a paper published in 1998, O'Connor, O’Connor and Abbas analysed viewers' descriptions of images and noted the tendency towards narrative description where narrative re- 
fers to instances where the viewers told little stories about the images, alluded to aspects of their own life story ("this reminds me of ...") or expressed frustration that they could not situate the image within a narrative. This study was carried out before widespread tagging through web 2.0 applications and is of interest in relation to this paper, because it is another instance of the image indexing story pointing relatively early on to new approaches to document description, acknowledging the polysemic nature of the sign and recognising the range of information seeking activities undertaken in relation to images. One of the challenges in social tagging has been to encourage creative input while at the same time disciplining input, for example, through the development of tag ontologies (see for example, Gruber 2007; Kim et al. 2008; Ding et al. 2010). Earlier templates (Rafferty and Hidderley 2005) have had limited success in practice. It might be that the ubiquitous and intuitive form of the story would allow the development of a relatively structured but intuitive method of inputting interpretative content.

\subsection{Final comments}

History might be characterised as the construction of organised narrative about human-experienced time, and the tendency of the historian is to smooth the stories so that they fit specific worldviews or theoretical frameworks. But, sometimes there are blips, disruptions, discordances and difficulties that disrupt the smoothness of historical narrative (see for example, discussions about history as narrative in White 1973; Stone 1979; Bruner 1991; Carr 1991). Information science and information retrieval is now at an historical stage that allows for broad brushed and sweeping historical narrative; however, this paper argues that the history of image retrieval presents the metanarrative of information retrieval, a metanarrative based on modernity and efficiency, with a little element of disruption.

Whilst accepting the general thrust of the modern metanarrative of modernity that emerges in the literature of knowledge organization and information retrieval, this paper offers a gentle reminder that image retrieval has always brought with it challenges regarding interpretation, decoding and readership that in many ways have only taken a central role in text retrieval solutions in the age of participatory digital culture and social media. With social media and the democratisation of authorship and readership, there have been moves towards the democratisation of indexing, but images posed their own knowledge representation and information management challenges before the widespread adoption of the web. And while conventional image retrieval tools have been developed in parallel with text retrieval tools, the literature of image retrieval has for many years provided reminders that the indexing and in- formation management of signifying documents is difficult.

As for the way ahead, there are a number of paths that could be, and are being pursued, including the notion of the iconic thesaurus, or perhaps more accurately the indexical iconic sign-based thesaurus for images, enhanced CBIR practices that incorporate recommender systems of various types and viewer-user oriented HCI design approaches, such as Dörk's flaneur-inspired approach. But wherever we go, it would seem that the certainty, uniformity and conventionality that tended to characterise information retrieval approaches of the mid-twentieth century, and which were interrogated so often in the research literature of image retrieval, have truly been superseded.

\section{References}

Alzu’bi, Ahmad, Abbes Amira, and Naeem Ramzan. 2015. "Semantic Content-based Image Retrieval: A Comprehensive Study." Journal of Visual Communication and Image Representation 32: 20-54.

Alexander, Arden and Tracy Meehleib. 2001. "The Thesaurus for Graphic Materials: Its History, Use, and Future." Cataloging \& Classification Quarterly 31, no. 3/4: 189-212.

Armitage, Linda H. and Peter G.B .Enser. 1997. "Analysis of User Need in Image Archives." Journal of Information Science 23: 287-99.

Baldoni, Matteo, Cristina Baroglio, Viviana Patti, and Paolo Rena. 2012. "From Tags to Emotions: Ontologydriven Sentiment Analysis in the Social Semantic Web." Intelligenza Artificiale 6, no. 1: 41-54.

Barthes, Roland, 1974. S/Z. New York: Hill and Wang.

Bennett, W. Lance and Livingston, Steven. 2018. "The Disinformation Order: Disruptive Communication and the Decline of Democratic Institutions." European Journal of Communication 33: 122-39.

Benson, Allen C. 2015. "Image Descriptions and their Relational Expressions: A Review of the Literature and the Issues." Journal of Documentation 71: 143-64.

Bohnsack, Ralf. 2009. "The Interpretation of Pictures and the Documentary Method." Historical Social Research/Historische Sozialforschung 34: 296-321.

Bruner, Jerome. 1991. "The Narrative Construction of Reality." Critical Inquiry 18, no 1: 1-21.

Bryant, Antony, Alistair Black, Frank Land, and Jaana Porra. 2013. "Information Systems History: What is History? What is IS History? What IS History? ... And Why Even Bother with History?” Journal of Information Technology 28, no. 1: 1-17, https://link.springer.com/article/10.1057/ jit.2013.3 
Cairns, Susan. 2013. "Mutualizing Museum Knowledge: Folksonomies and the Changing Shape of Expertise." Curator: The Museum Journal 56: 107-19.

Carr, David. 1991. Time, Narrative, and History. Indianapolis: Indiana University Press.

Carr, Edward Hallett. 1961. What is History? London: Macmillan.

Chen, Tao, Damian Borth, Trevor Darrell, and Shih-Fu Chang. 2014. "Deepsentibank: Visual Sentiment Concept Classification with Deep Convolutional Neural Networks." CoRR, arXiv http:/ / arxiv.org/abs/1410.8586

Choi, Youngok and Edie M. Rasmussen. 2003. "Searching for Images: The Analysis of Users' Queries for Image Retrieval in American History." Journal of the Association for Information Science and Technology 54: 498-511.

Collingwood, Robin George. 1994. The Idea of History. Oxford: Oxford University Press.

Collins, Karen. 1998. "Providing Subject Access to Images: A Study of User Queries." The American Archivist 61: 36-55.

Conduit, Neil and Pauline Rafferty. 2007. "Constructing an Image Indexing Template for The Children's Society: Users' Queries and Archivists' Practice. Journal of Documentation 63: 898-919.

Datta, Ritendra, Dhiraj Joshi, Jia Li, and James Z. Wang. 2006. "Studying aesthetics in Photographic Images using a Computational Approach." In 9th European Conference on Computer Vision, Graz, Austria, May 7-13, 2006, Proceedings, ed. A. Leonardis, H. Bischof, and A. Pinz. Lecture Notes in Computer Science 3953. Berlin: Springer, 288-301. doi:10.1007/11744078_23

Day, Ronald E. 2008. The Modern Invention of Information: Discourse, History, and Power. Carbondale, IL: SIU Press.

Day, Ronald E. 2014. Indexing It All: The Subject in the Age of Documentation, Information, and Data. Cambridge, MA: MIT Press.

Ding, Ying, Elin K. Jacob, Michael Fried, Ioan Toma, Erjia Yan, Schubert Foo, and Staša Milojević. 2010. "Upper Tag Ontology for Integrating Social Tagging Data." Journal of the Association for Information Science and Technology 61: 505-21.

Dörk, Marian, Sheelagh Carpendale, and Carey Williamson. 2011. "The Information Flaneur: A Fresh Look at Information Seeking." Proceedings of the SIGCHI Conference on Human Factors in Computing Systems. New York: ACM, 1215-24.

Dousa, Thomas. 2007. "Everything Old is New Again: Perspectivism and Polyhierarchy in Julius O. Kaiser's Theory of Systematic Indexing." Paper delivered at the 2007 ASIST SIG/CR Meeting, Milwaukee, Wisconsin. https://repository.arizona.edu/handle/10150/105780

Dubinko, Micah, Ravi Kumar, Joseph Magnani, Jasmine Novak, Prabhakar Raghavan, and Andrew Tomkins.
2007. "Visualizing Tags over Time." ACM Transactions on the $W e b 1$, no. 2, article 7. doi:10.1145/1255438.1255439

Enser, Peter. G. B. 1995. "Progress in Documentation: Pictorial Information Retrieval." Journal of Documentation 51: 126-70.

Enser, Peter. G. B. 2000. “Visual Image Retrieval: Seeking the Alliance of Concept-based and Content-based Paradigms." Journal of Information Science 26: 199-210.

Enser, Peter. G. B. 2008a “The Evolution of Visual Information Retrieval." Journal of Information Science 3: 531-46.

Enser, Peter. G. B. 2008b. "Visual Image Retrieval." Annual Review of Information Science and Technology 42: 1-42.

Feinberg, Melanie. 2006. An Examination of Authority in Social Classification Systems." Advances in Classification Research Online 17, no. 1: 1-11.

Fidel, Raya. 1997. "The Image Retrieval Task: Implications for the Design and Evaluation of Image Databases." New Review of Hypermedia and Multimedia 3, no. 1: 181-99.

Garcia-Marco, Francisco-Javier. 2016. "Enhancing the Visibility and Relevance of Thesauri in the Web: Searching for a Hub in the Linked Data Environment." Knowledge Organization 43: 193-202.

Godoy, Daniela and Alejandro Corbellini. 2016. "Folksonomy-Based Recommender Systems: A State-of-the-Art Review." International Journal of Intelligent Systems 31: 31446.

Gruber, Thomas. 2007. "Ontology of Folksonomy: A Mash-up of Apples and Oranges." International Journal on Semantic Web and Information Systems 3, no. 1: 1-11.

Gudivada, Venkat. N. and Vijay. V. Raghavan. 1995. Picture Retrieval systems: A Unified Perspective and Research Issues. Computer Science Technical Report CS9503. Athens: Ohio University.

Guy, Marieke and Emma Tonkin, 2006, "Folksonomies: Tidying up Tags?” D-Lib Magazine 12, no. 1. http:// www.dlib.org/dlib/january06/guy/01guy.html

Hare, Jonathon S., Paul H. Lewis, Peter G. B. Enser, and Christine J. Sandom. 2006. "Mind the Gap: Another Look at the Problem of the Semantic Gap in Image Retrieval." Paper presented at IS\&T [Society for Imaging Science and Technology)/SPIE [International Society for Optics and Photonics] 18 $8^{\text {th }}$ Annual Symposium, Electronic Imagin Science and Technology, 15-19 January 2007, San Jose, Calif.

Hayles, N. Katherine. 2008. How we became Posthuman: Virtual Bodies in Cybernetics, Literature, and Informatics. Chicago: University of Chicago Press.

Hidderley, Rob and Pauline Rafferty. 1997. "Democratic Indexing: An Approach to the Retrieval of Fiction." Information Services \& Use 17: 101-9.

Hidderley, Rob and Pauline Rafferty. 2005. Indexing Multimedia and Creative Works: The Problems of Meaning and Interpretation. Farnham: Ashgate Publishing. 
Hodge, Bob and Gunther. Kress, 1988. Social Semiotics. Cambridge: Polity.

Huizinga, Johan. 1971. Homo Ludens: A Study of the PlayElement in Culture. Boston: Beacon.

Jansen, Bernard J. 2008. "Searching for Digital Images on the Web." Journal of Documentation 64: 81-101.

Jauss, Hans Robert; Elizabeth Benzinger. 1970. "Literary History as a Challenge to Literary Theory." New Literary History 2: 7-37.

Jorgensen, Corinne. 1995. "Classifying Images: Criteria for Grouping as Revealed in a Sorting Task." Advances in Classification Research Online 6, no. 1: 65-78.

Jorgensen, Corinne. 1998. "Attributes of Images in Describing Tasks." Information Processing \& Management 34: 161-74.

Joshi, Dhiraj, Ritendra Datta, Elena Fedorovskaya, QuangTuan Luong, James Z. Wang, Jia Li, and Jiebo Luo. 2011. "Aesthetics and Emotions in Images." IEEE Signal Processing Magazine 28, no. 5: 94-115.

Kim, Hak Lae, Alexandre Passant, John G. Breslin, Simon Scerri, and Stefan Decker. 2008. "Review and Alignment of Tag Ontologies for Semantically-linked Data in Collaborative Tagging Spaces." Proceedings IEEE International Conference on Semantic Computing 2008 4-7 August 2008 Santa Clara, California. Los Alamitos, CA: IEEE Computer Society, 315-22.

Krause, Michael. G. 1988. "Intellectual Problems of Indexing Picture Collections.” Audiovisual Librarian 14: 73-81.

Kroski, Ellyssa. 2005. "The Hive Mind: Folksonomies and User-based Tagging." InfoTangle (blog), December 7.

Mai, Jens-Erik. 1999. "A Postmodern Theory of Knowledge Organization." In ASIS 99: Proceedings of the 62nd ASIS Annual Meeting, Washington, DC, October 31-November 4, 1999; Knowledge, Creation, Organization and Use, ed. Larry Woods. Proceedings of the ASIS Annual Meeting 36. Medford, N.J.: Information Today, 547-56.

Mai, Jens-Erik. 2004. "Classification in Context: Relativity, Reality, and Representation." Knowledge Organization 31: 39-48.

Mai, Jens-Erik. 2011. "Folksonomies and the New Order: Authority in the Digital Disorder." Knowledge Organization 38: 114-22.

Mathes, Adam. 2004. "Folksonomies-Cooperative Classification and Communication through Shared Metadata." htttp://www.adammathes.com/academic/computermediated-communication/folksonomies.html

Matusiak, Krystyna K. 2006. “Towards User-Centered Indexing in Digital Image Collections.” OCLC Systems \& Services: International Digital Library Perspectives 22: 283-98.

Merholz, Peter. 2005. "Metadata for the Masses." AdaptivePath.org (blog), Oct. 19. http://adaptivepath.com/ideas/ e000361
Nam, Hyoryung and Pallassana Krishnan Kannan. 2014. "The Informational Value of Social Tagging Networks." Journal of Marketing 78, no. 4: 21 -40.

O’Connor, Brian C, Mary K O’Connor, and June M. Abbas. 1999. "User Reactions as Access Mechanism: An Exploration Based on Captions for Images." Journal of the Association for Information Science and Technology 50: 681-97.

Pan, Yingwei, Ting Yao, Tao Mei, Houqiang Li, ChongWah Ngo, and Yong Rui. 2014. "Click-through-based cross-view Learning for Image Search.” In Proceedings Of The 37th International ACM SIGIR Conference On Research \& Development In Information Retrieval. New York: ACM, 717-26.

Panofsky, Erwin. 1993. Meaning in the Visual Arts. Harmondsworth: Penguin.

Rafferty, Pauline. 2001. "The Representation of Knowledge in Library Classification Schemes." Knowledge Organization 28: 180-91.

Rafferty, Pauline. 2011. "Informative Tagging of Images: The Importance of Modality in Interpretation". Knowledge Organization 38: 283-98.

Rafferty, Pauline and Fawaz Albinfalah. 2014. "A Tale of Two Images: The Quest to Create a Story-based Image Indexing System.” Journal of Documentation 70: 605-21.

Rafferty, Pauline and Rob Hidderley. 2007. "Flickr and Democratic Indexing: Dialogic Approaches to Indexing." Aslib Proceedings 59: 397-410.

Rayward, W. Boyd. 2014. "Information Revolutions, The Information Society, and the Future of the History of Information Science." Library Trends 62, no. 3: 681-713.

Ristoski, Peta, and Heiko Paulheim. 2016. "Semantic Web in Data Mining and Knowledge Discovery: A Comprehensive Survey." Web Semantics: Science, Services and Agents on the World Wide Web 36: 1-22.

Rorissa, Abebe. 2010. "A Comparative Study of Flickr Tags and Index Terms in a General Image Collection." Journal of the Association for Information Science and Technology 61: 2230-42.

Rowley, Jennifer. 1994. “The Controlled Versus Natural Indexing Languages Debate Revisited: A Perspective on Information Retrieval Practice and Research." Journal of Information Science 20: 108-18.

Sanderson, Mark and W. Bruce Croft. 2012. "The History of Information Retrieval Research." Proceedings of the IEEE 100: 1444-51. doi:10.1109/JPROC.2012.2189916

Shatford, Sara. 1986. "Analyzing the Subject of a Picture: A Theoretical Approach." Cataloging \& Classification Quarterly 6, no 3: 39-62.

Shatford Layne, Sara. 1994. "Some Issues in the Indexing of Images." Journal of the American Society for Information Science 45: 583-88. 
Shirky, Clay. 2005. "Ontology is Overrated: Categories, Links, Tags.” Clay Shirky's Writings About the Internet (blog). http://shirky.com/writings/ontology_overrated.html

Schou, Jannick and Johan Farkas. 2016. "Algorithms, Interfaces, and the Circulation of Information: Interrogating the Epistemological Challenges of Facebook." KOME: An International Journal of Pure Communication Inquiry 4: 36-49.

Smeulders, Arnold W.M., Marcel Worring, Simone Santini, Amarnath Gupta, and Ramesh Jain. 2000. "Contentbased Image Retrieval at the End of the Early Years." IEEE Transactions on Pattern Analysis and Machine Intelligence 22: 1349-80.

Stone, Lawrence. 1979. “The Revival of Narrative: Reflections on a New Old History.” Past \& Present 85: 3-24.

Surowiecki, James. 2005. The Wisdom of Crowds. New York: Anchor.

Trant, Jennifer. 2006. "Exploring the Potential for Social Tagging and Folksonomy in Art Museums: Proof of Concept." New Review of Hypermedia and Multimedia 12, no. 1: 83-105.

Trevisiol, Michele, Luca Chiarandini, Luca Maria Aiello, and Alejandro Jaimes. 2012. "Image Ranking Based on
User Browsing Behavior." In Proceedings of the 35 th International ACM SIGIR Conference on Research and Development in Information Retrieval. New York: ACM, 445-54.

White, Hayden. 1973. Metahistory: The Historical Imagination in Nineteenth-Century Europe. Baltimore: Johns Hopkins University Press.

Whitelaw, Mitchell. 2012. "Towards Generous Interfaces for Archival Collections." Comma 2012, no. 2: 123-132.

Whitelaw, Mitchell. 2015. "Generous Interfaces for Digital Cultural Collections.” Digital Humanities Quarterly 9, no. 1. http://www.digitalhumanities.org/dhq/vol/9/1/00 0205/000205.html

Wray, Tim, Peter Eklund, and Karlheinz Kautz. 2013 "Pathways through Information Landscapes: Alternative Design Criteria for Digital Art Collections." In ICIS 2013 Proceedings. https://aisel.aisnet.org/icis2013/proceedings/GlobalIssues/1/

Zhu, Lei, Jialie Shen, Liang Xie, and Zhiyong Cheng. 2017. "Unsupervised Visual Hashing with Semantic Assistant for Content-based Image Retrieval." In IEEE Transactions on Knowledge and Data Engineering 29: 472-86. 